Check for updates

Cite this: RSC Adv., 2019, 9, 39986

\title{
Enhanced thermal conductivity and mechanical properties of a GNP reinforced $\mathrm{Si}_{3} \mathrm{~N}_{4}$ composite
}

\author{
Adil Saleem, ${ }^{\text {ab }}$ Yujun Zhang, ${ }^{* a b}$ Hongyu Gong, (D) *ab Muhammad K. Majeed, ${ }^{c}$ \\ Jie Jing, ${ }^{\text {ab }}$ Xiao Lin $^{\text {ab }}$ and M. Zeeshan Ashfaq ${ }^{\mathrm{ab}}$
}

Graphene nanocomposites can significantly enhance the thermal conductivity and mechanical properties of ceramics at relatively low nano-filler addition. Herein, graphene nano-platelet reinforced $\mathrm{Si}_{3} \mathrm{~N}_{4}(\mathrm{GNP} /$ $\mathrm{Si}_{3} \mathrm{~N}_{4}$ ) composites were prepared by hot press (HP) sintering using fluoride $\left(\mathrm{AlF}_{3}, \mathrm{MgF}_{2}\right)$ sinteringadditives. The microstructural properties revealed the enhanced crystallization degree and density of the GNP/Si ${ }_{3} \mathrm{~N}_{4}$ composites with different concentrations of graphene nano-platelets (GNPs). These properties help to achieve a significantly improved thermal conductivity (from 82.42 to $137.47 \mathrm{~W} \mathrm{~m}^{-1}$ $\mathrm{K}^{-1}$ ) of the GNP/Si${ }_{3} \mathrm{~N}_{4}$ composites. The morphology of the composites shows a uniform distribution of GNP, whereas overlapping of GNPs (2 to 4 platelets) at the grain boundaries of $\mathrm{Si}_{3} \mathrm{~N}_{4}$ was observed. The fracture toughness and Vickers hardness of the composites also increased with the increasing content of GNP. The toughening mechanism was similar in all composites with GNP addition in respect of pull out, crack deflection, crack branching and crack bridging.

Received 8th November 2019

Accepted 16th November 2019

DOI: 10.1039/c9ra09286b

rsc.li/rsc-advances
CNT tend to form bundles and ropes as well as agglomerate by reducing their promising influence on functional and mechanical properties. Nowadays, $\mathrm{sp}^{2}$-hybridized carbon atom (graphene monolayer), arranged in a 2-D lattice, has attracted great consideration, owing to its unique mechanical, electrical and thermal properties. ${ }^{10}$ There are different techniques including micro-mechanical exfoliation of graphite, growth by chemical vapor deposition and development upon a crystalline silicon carbide to produce defect (D)-free graphene (carbon) with excellent features. ${ }^{11}$ In the present era, a new cost-effective superior quality carbon-based filament phases in the form of GNP have been developed, also known as multilayer GNP, are an alternate to CNT. These platelets consist of many layers compared to the mono-layered graphene. GNP with various desired ranges (e.g. length and width of $\sim 0.05-10 \mathrm{~m}$, and thickness of $\sim 1-10 \mathrm{~nm}$ ) offer an excellent combination of high thermal conductivity, electrical and mechanical properties. ${ }^{\mathbf{1 2 , 1 3}}$ As compared to the neat polymers, GNPs have already been used to enhance the mechanical, thermal and electrical properties of materials. ${ }^{14}$ Wang $^{15}$ reported $\mathrm{GNP} / \mathrm{Al}_{2} \mathrm{O}_{3}$ composite with improved fracture toughness, attributed to the bridging and pulling out of nano-sheets. Accordingly, fracture toughness and conductivity of $\mathrm{GNP} / \mathrm{Al}_{2} \mathrm{O}_{3}$ composites are $\sim 53 \%$ and 13 orders of the magnitude greater than those without GNP doped $\mathrm{Al}_{2} \mathrm{O}_{3}$ material, respectively. Kun ${ }^{\mathbf{1 6}}$ fabricated $\mathrm{Si}_{3} \mathrm{~N}_{4}$ based nanocomposites with different contents of graphene fillers. According to their results, the bending strength and elastic modulus reduced due to the addition of graphene content. Kvetkova ${ }^{17}$ and Dusza ${ }^{18}$ presented different types of graphene fillers reinforced $\mathrm{Si}_{3} \mathrm{~N}_{4}$ ceramics, which enhanced their fracture 
toughness. Those identified toughening factors were crack branching, deflection and bridging.

Over the last decades, aluminum nitride ( $\mathrm{AlN}$ ) has been used as a major ceramic material for power devices due to its high thermal conductivity. However it has poor mechanical properties and low chemical stability, resulting in low reliability of the substrates. ${ }^{19}$ Alternative highly thermally conductive materials with good mechanical properties were required to secure thermomechanical reliability, therefore attention turned to $\mathrm{Si}_{3} \mathrm{~N}_{4}$ ceramics. Hence, $\mathrm{Si}_{3} \mathrm{~N}_{4}$ with improved thermal conductivity and good mechanical properties could be definitely an attractive ceramic material for high power electronic devices. ${ }^{20}$ The thermal properties of $\mathrm{Si}_{3} \mathrm{~N}_{4}$ is also greatly influenced by particle size, processing conditions and lattice oxygen content. Zhou ${ }^{20}$ presented that more reducing atmosphere during the nitridation process can considerably improve the thermal conductivity of $\mathrm{Si}_{3} \mathrm{~N}_{4}$ by developing $\beta-\mathrm{Si}_{3} \mathrm{~N}_{4}$ phase while lowering the lattice oxygen content. It is well known that graphite has also a strong reduction capability, especially at high temperatures. A powder bed containing graphite can be used during nitridation and sintering, which is possibly effective to increase the thermal conductivity of $\mathrm{Si}_{3} \mathrm{~N}_{4}$. In the past studies, researchers found out that the addition of graphene into ceramics matrix can considerably improve the thermal conductivity during sintering. ${ }^{21-24}$ Kargar $^{25}$ investigated electromagnetic interface shielding efficiency and thermal conductivity of epoxy-based composites reinforced with graphene and revealed an effective total shielding efficiency $45 \mathrm{~dB}$ (X-band), while at the same time providing high thermal conductivity $8 \mathrm{~W} \mathrm{~m}^{-1} \mathrm{~K}^{-1}$. Renteria ${ }^{26}$ described that the graphene fillers in phase change materials is potentially promising for thermal management of high power battery packs.

From the above discussion we can conclude that the GNP can efficiently enhance the mechanical and thermal properties of the $\mathrm{GNP} / \mathrm{Si}_{3} \mathrm{~N}_{4}$ ceramic composites. However, thermal stability of GNP structure is related to the sintering parameters which can affect the microstructure and thermal stability of GNP. Inam ${ }^{27}$ have investigated the thermal stability of ceramic composites by Raman study and reported that the graphene structure was closely connected with graphitization degree during sintering process. Nieto ${ }^{28}$ have observed the effect of sintering parameters on thermal stability of GNP and found that the short holding time, high pressure and low temperature can significantly improve the densification and grain growth suppression. Furthermore, Wang ${ }^{29}$ have determined the optimal sintering parameters to improve the thermal stability of graphene and mechanical properties of graphene reinforced $\mathrm{Al}_{2} \mathrm{O}_{3}$ composites. The focus of current research contribution is to study the effect of the GNP addition on thermal conductivity and mechanical properties of $\mathrm{HP}$ sintered $\mathrm{GNP} / \mathrm{Si}_{3} \mathrm{~N}_{4}$ composites. To the best of our knowledge, a very few reports have been studied showing the GNP reinforced $\mathrm{Si}_{3} \mathrm{~N}_{4}$ composites with improved thermal conductivity. Therefore, GNP/ $\mathrm{Si}_{3} \mathrm{~N}_{4}$ composite is very interesting as a new multifunctional material with enhanced thermal conductivity as well as high mechanical properties.

\section{Experimental procedure}

The raw materials were $\alpha-\mathrm{Si}_{3} \mathrm{~N}_{4}(0.5 \mu \mathrm{m}$ particle size, purity $>$ 93\%, Beijing Ziguang), GNP as a filler content, $2.5 \mathrm{wt} \%$ aluminum fluoride $\left(\mathrm{AlF}_{3}\right)$ and $2.5 \mathrm{wt} \%$ magnesium fluoride $\left(\mathrm{MgF}_{2}\right.$, Shanghai Macklin Biochemical Technology) as a sintering additives were used. Different ratios of GNP $(0,1,2$ and $3 \mathrm{wt} \%)$ and $\alpha-\mathrm{Si}_{3} \mathrm{~N}_{4}$ powders were blended to obtain homogenous mixtures. In order to increase the sintering activity and nitridation rate, the powder mixtures having different contents of GNP and $\alpha-\mathrm{Si}_{3} \mathrm{~N}_{4}$, with constant wt $\%$ of sintering-additives were crushed in a ball mill machine with ethyl alcohol for 25 minutes. After drying and sieving, the resulting powders were transferred into a graphite mold of $42 \mathrm{~mm}$ in diameter, graphite papers with $1 \mathrm{~mm}$ thickness were placed between the powders and the mold. The densification took place by HP sintering at $1650{ }^{\circ} \mathrm{C}$ in high purity $\mathrm{N}_{2}$ atmosphere at pressure of $40 \mathrm{MPa}$ for 2 hours and the heating rate was $10{ }^{\circ} \mathrm{C} \min ^{-1}$.

Archimedes method have been used to analyze the density of as-prepared composites and the relative density of samples was calculated according to the ratio of measured bulk density to theoretical density. The phases present in as-prepared composites were identified by X-ray diffraction (XRD, D/MAXUltima IV, $\lambda=1.5418 \AA$ ). The microstructural properties were carried out using field emission scanning electron microscope (FESEM, JSM-7800F), equipped with energy dispersive spectra analyser (EDS) to examine the elemental composition. Carbon phases in the ceramics were analyzed by the Raman spectra using Raman spectroscopy (Renishaw, RMS, UK). Vickers indentation (Akashi Corp., AVK-C2) was used to measure the Vickers hardness with the load of $10 \mathrm{~N}$ (dwell time of $15 \mathrm{~s}$ ). The flexural strength was measured using a 3-point bending method with sample size of $4 \times 3 \times 40 \mathrm{~mm}^{3}$, by a span of $20 \mathrm{~mm}$ and a crosshead speed of $0.5 \mathrm{~mm} \mathrm{~min}^{-1}$ with a universal testing machine (Electromechanical Universal Testing Machine, CMT5105). The single edge notched beam (SENB) method was used to measure the fracture toughness with the sample size of $4 \times 2 \times 40 \mathrm{~mm}^{3}$, using a span of $20 \mathrm{~mm}$ and a crosshead speed of $0.05 \mathrm{~mm} \mathrm{~min}^{-1}$ with a universal testing machine (CMT5105, Electromechanical Universal Testing Machine). Thermal conductivity $(K)$ of all the composites was examined from the observed values of thermal diffusivity $(\alpha)$ by using a macro flash machine (Hyperflash, LFA 467), density and known heat capacity $\left(c_{\mathrm{p}}=0.68 \mathrm{~J} \mathrm{~g}^{-1} \mathrm{~K}^{-1}\right)$.

\section{Results and discussion}

Fig. $1 \mathrm{a}$ and $\mathrm{b}$ shows the SEM images of globular shape $\alpha-\mathrm{Si}_{3} \mathrm{~N}_{4}$ and GNP fillers used as a reinforcing material which were geometrically different regarding to their width, length and thickness. XRD analysis of HP sintered $\mathrm{GNP} / \mathrm{Si}_{3} \mathrm{~N}_{4}$ composites fabricated with different concentrations of GNP can be observed in Fig. 1c. It can be observed that the main diffraction peaks corresponds to the dominant $\beta-\mathrm{Si}_{3} \mathrm{~N}_{4}$ and no extra peaks of residual $\alpha-\mathrm{Si}_{3} \mathrm{~N}_{4}$ have been identified, suggesting full phase transformation from $\alpha$ - to $\beta-\mathrm{Si}_{3} \mathrm{~N}_{4}$ at $1650{ }^{\circ} \mathrm{C}$ during $\mathrm{HP}$ sintering. In all GNP reinforced composites, the carbon peak at 

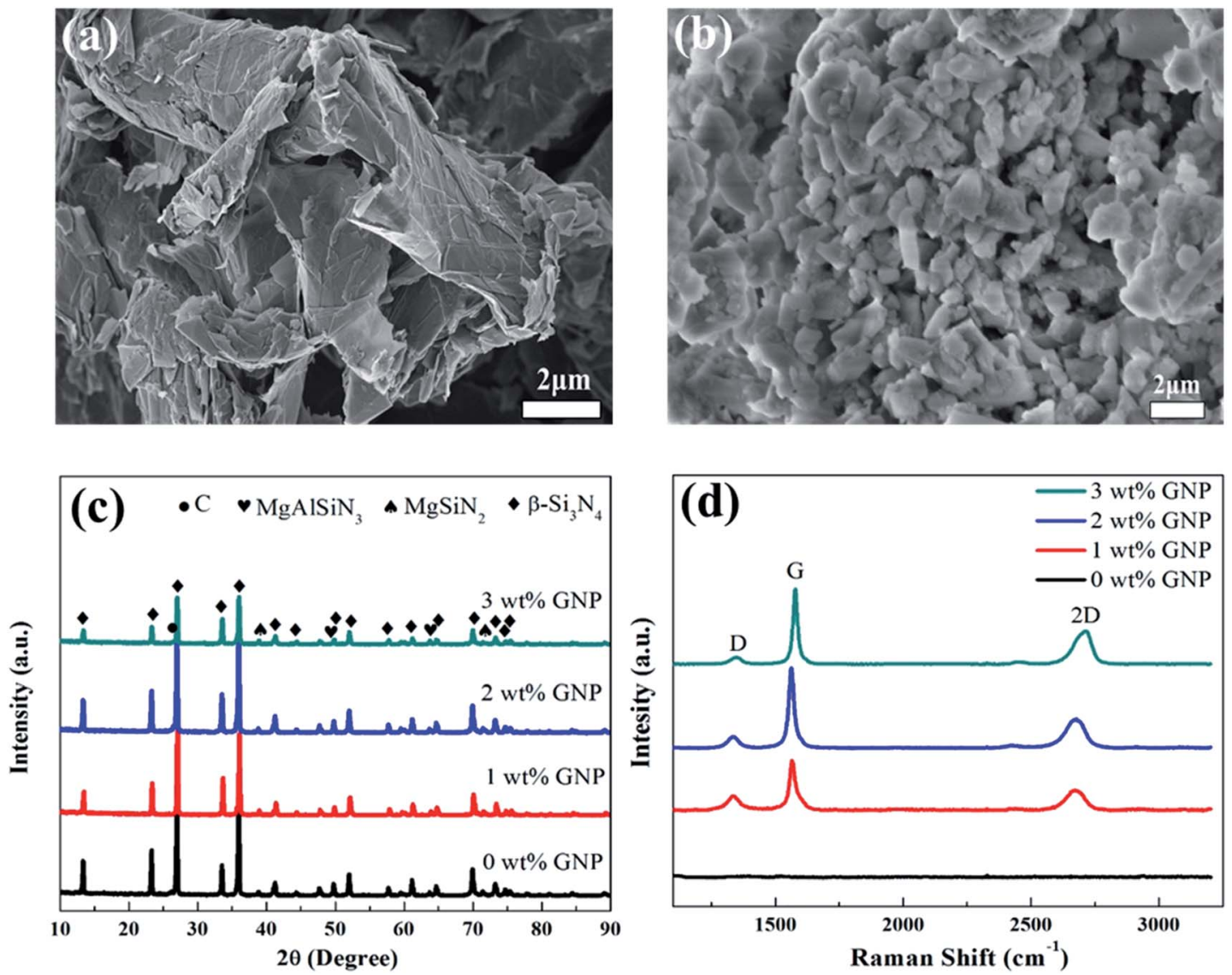

Fig. 1 SEM images for raw GNP (a) raw $\alpha-\mathrm{Si}_{3} \mathrm{~N}_{4}$ (b). XRD patterns (c) and Raman analysis (d) for GNP/Si $\mathrm{N}_{4}$ composites at different wt\% of GNP.

$26.4^{\circ}$ has been detected which confirmed the presence of GNP and no other carbon-phase formed. A few extra peaks of $\mathrm{MgAlSiN}_{3}$ and $\mathrm{MgSiN}_{2}$ have also been identified, which may ascribe to the reaction between $\mathrm{Si}_{3} \mathrm{~N}_{4}$ and sintering additives $\left(\mathrm{AlF}_{3}, \mathrm{MgF}_{2}\right)$ during sintering mechanism. At the subsequent time, $\alpha-\mathrm{Si}_{3} \mathrm{~N}_{4}$ particles dissolved in liquid-phase, encouraging a re-precipitation and local supersaturation of $\beta-\mathrm{Si}_{3} \mathrm{~N}_{4} \cdot{ }^{30}$ Previous investigations showed that the fluoride doped $\mathrm{Si}_{3} \mathrm{~N}_{4}$ ceramics can facilitate the transformation of $\alpha$ - to $\beta-\mathrm{Si}_{3} \mathrm{~N}_{4}$ more strongly than that of oxygen containing additives. ${ }^{31,32}$ The Raman spectroscopy can definitely determine the carbon phase in the composites. ${ }^{33}$ Generally, the $G$ band signifies the stretching vibration of the graphitic lattice plane while the D band represents graphitic lattice defects and the change of structure disorder. The Raman spectra of GNP/Si ${ }_{3} \mathrm{~N}_{4}$ composites with different graphene content can be observed in Fig. 1d. Two main prominent peaks at $\sim 1333 \mathrm{~cm}^{-1}$ (D band) and $\sim 1565 \mathrm{~cm}^{-1}$ (G band) represent the carbon $\mathrm{sp}^{3}$ hybridized (D) and carbon $\mathrm{sp}^{2}$ hybridized (G), respectively showing the presence of free carbon. ${ }^{34}$ The 2D peak at $\sim 2677 \mathrm{~cm}^{-1}$ shows the thinning of multilayer GNP into few layers or promising bi-layer graphene. The graphene structure can transform from multilayers into single layer or bi-layers graphene at a high temperature and pressure during HP sintering. The intensity of all bands become more prominent due to the increase of GNP concentration. ${ }^{35}$ Generally, the intensity ratio of D and $\mathrm{G}$ band
$\left(I_{\mathrm{D}} / I_{\mathrm{G}}\right)$ is used to examine the structural changes and stability of graphene. From Table 1, the decrease in $I_{\mathrm{D}} / I_{\mathrm{G}}$ values with the increasing content of GNP shows the defect free structure, suggesting the inhibition of GNP agglomeration. ${ }^{36}$ SEM images of fractured surfaces of composites can be seen in Fig. 2. The rod-like narrow grain size $\beta-\mathrm{Si}_{3} \mathrm{~N}_{4}$ particles can clearly be observed with high mean aspect ratio in $\mathrm{GNP} / \mathrm{Si}_{3} \mathrm{~N}_{4}$ composites. This rod-like $\beta$ phase leads to an increase in fracture toughness, and the toughening mechanism is the same as in the whisker reinforced composites, such as grain pull out and grain bridging by elongated grains. ${ }^{37}$ The GNP relatively homogeneously distributed across all the composites, and no GNP clusters were found with a shape characteristic for CNT and CNF reinforced system. ${ }^{38}$ The sites in which porosity or grain pull out could be assumed are the sites with GNP, partially damaged during grinding and polishing. The characteristic crack deflection on the fractured surface and the bridging mechanism by smaller GNP can be observed, pulling the interior from the outside and the GNP fracture has a high interface strength. A similar mechanism of bridges, the crack propagating in bridging region of crack far behind the crack tip. According to Walker, $^{3}$ a similar mechanism of GNP was observed which were pulled out and wrapped around the matrix particles. It has been expected that the energy required to pull out the platelets is greater than the energy required for nanofibers due to platelet entanglement around the grain 
Table 1 Thermal conductivity, Vickers hardness, fracture toughness and flexural strength for GNP/Si ${ }_{3} \mathrm{~N}_{4}$ composites at different wt\% of GNP

\begin{tabular}{|c|c|c|c|c|c|}
\hline Composites & $I_{\mathrm{D}} / I_{\mathrm{G}}$ & $\begin{array}{l}\text { Thermal conductivity } \\
\left(\mathrm{W} \mathrm{m}^{-1} \mathrm{~K}^{-1}\right)\end{array}$ & $\begin{array}{l}\text { Vickers hardness } \\
\text { (HV) }\end{array}$ & $\begin{array}{l}\text { Fracture toughness } \\
\left(\mathrm{MPa} \mathrm{m}^{0.5}\right)\end{array}$ & $\begin{array}{l}\text { Flexural strength } \\
\text { (MPa) }\end{array}$ \\
\hline $\mathrm{Si}_{3} \mathrm{~N}_{4}-0 \mathrm{wt} \% \mathrm{GNP}$ & - & 82.42 & $1561 \pm 19$ & $5.08 \pm 0.0$ & $516 \pm 7$ \\
\hline $\mathrm{Si}_{3} \mathrm{~N}_{4}-2 \mathrm{wt} \% \mathrm{GNP}$ & 0.14 & 137.47 & $1889 \pm 24$ & $11.26 \pm 0.35$ & $617 \pm 35$ \\
\hline $\mathrm{Si}_{3} \mathrm{~N}_{4}-3$ wt $\%$ GNP & 0.09 & 127.81 & $1862 \pm 11$ & $9.51 \pm 0.21$ & $599 \pm 22$ \\
\hline
\end{tabular}

boundaries of the matrix and the increased contact area in the HP sintered composite. According to the EDS spectra, Fig. 3 confirms the presence of all the elements i.e. Si, N, C, Al, Mg and F.

Generally, the bulk density of a composite shows how efficiently the composite has been treated. In ceramics, the mechanical properties of bulk materials can be influenced by density of the composite. Therefore, highly dense composites are preferred for ceramics, since the porosity can attribute to defects. It has been reported earlier that the use of fluoride additives can decrease the lattice oxygen contents and porosity of the composites. ${ }^{31,39}$ The bulk and relative densities of HP sintered $\mathrm{GNP} / \mathrm{Si}_{3} \mathrm{~N}_{4}$ composites with different GNP content are plotted in Fig. 4a. It can be noticed that the bulk and relative densities of $\mathrm{HP}$ sintered $\mathrm{GNP} / \mathrm{Si}_{3} \mathrm{~N}_{4}$ composites are relatively high. However, the monolithic $\mathrm{Si}_{3} \mathrm{~N}_{4}$ is fully dense, on the other hand, the $\mathrm{GNP} / \mathrm{Si}_{3} \mathrm{~N}_{4}$ composites contain some pores in it, which can be attributed to the overlapping of more GNP as observed by the SEM images. ${ }^{40}$ Both the bulk and relative densities of the prepared composites reached to a maximum value at $0 \mathrm{wt} \%$ fraction of GNP. As shown in Table 1, the addition of fillers affect the densifying process, which means the presence of GNP reduces the active material density. On the other hand, the density of GNP is significantly lower than that of crystalline $\mathrm{Si}_{3} \mathrm{~N}_{4}$, thus the overall bulk density of the GNP/Si ${ }_{3} \mathrm{~N}_{4}$ composites becomes lower with the addition of different GNP content. As the flexibility of aggregated GNP decreases, an increase in the proportion of GNP tends to aggregate, resulting in the formation of extra pores within the interface between GNP and $\mathrm{Si}_{3} \mathrm{~N}_{4}$ matrix. Industrially synthesized raw powder $\alpha$ $\mathrm{Si}_{3} \mathrm{~N}_{4}$, transforms into the more stable $\beta-\mathrm{Si}_{3} \mathrm{~N}_{4}$ during high temperature liquid phase sintering, resulting in well-developed fibrous grains microstructure. The real value of industrially available high thermal conductive $\mathrm{Si}_{3} \mathrm{~N}_{4}$ is substantially low i.e. 60 to $90 \mathrm{~W} \mathrm{~m} \mathrm{~m}^{-1}$. Although, the estimated theoretical thermal conductivity value of $\beta-\mathrm{Si}_{3} \mathrm{~N}_{4}$ is higher. ${ }^{20}$ The thermal conductivity $(K)$ of $\mathrm{GNP} / \mathrm{Si}_{3} \mathrm{~N}_{4}$ composites have been determined by using eqn (1).

$$
K=\alpha \rho c_{\mathrm{p}}
$$

where ' $\alpha$ ' is thermal diffusivity, ' $\rho$ ' is density and ' $c_{\mathrm{p}}$ ' is heat capacity $\left(c_{\mathrm{p}}=0.68 \mathrm{~J} \mathrm{~g}^{-1} \mathrm{~K}^{-1}\right) .{ }^{\mathbf{4 1}}$ The thermal conductivities of the $\mathrm{HP}$ sintered $\mathrm{GNP} / \mathrm{Si}_{3} \mathrm{~N}_{4}$ composites are plotted in Fig. $4 \mathrm{~b}$. It can
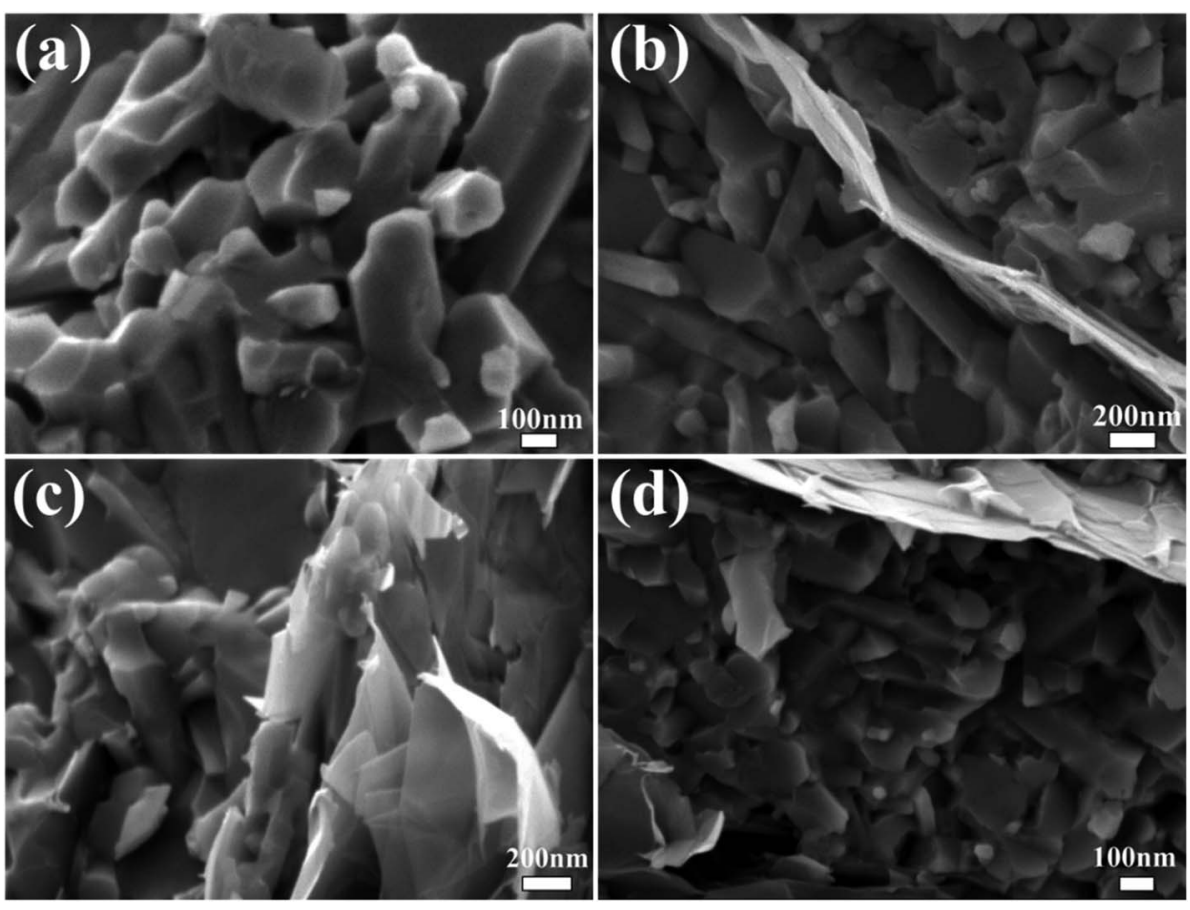

Fig. 2 SEM images of the fractured surface for GNP/Si $3 \mathrm{~N}_{4}$ composites at 0 wt\% (a), 1 wt\% (b), 2 wt\% (c) and 3 wt\% (d) of GNP. 


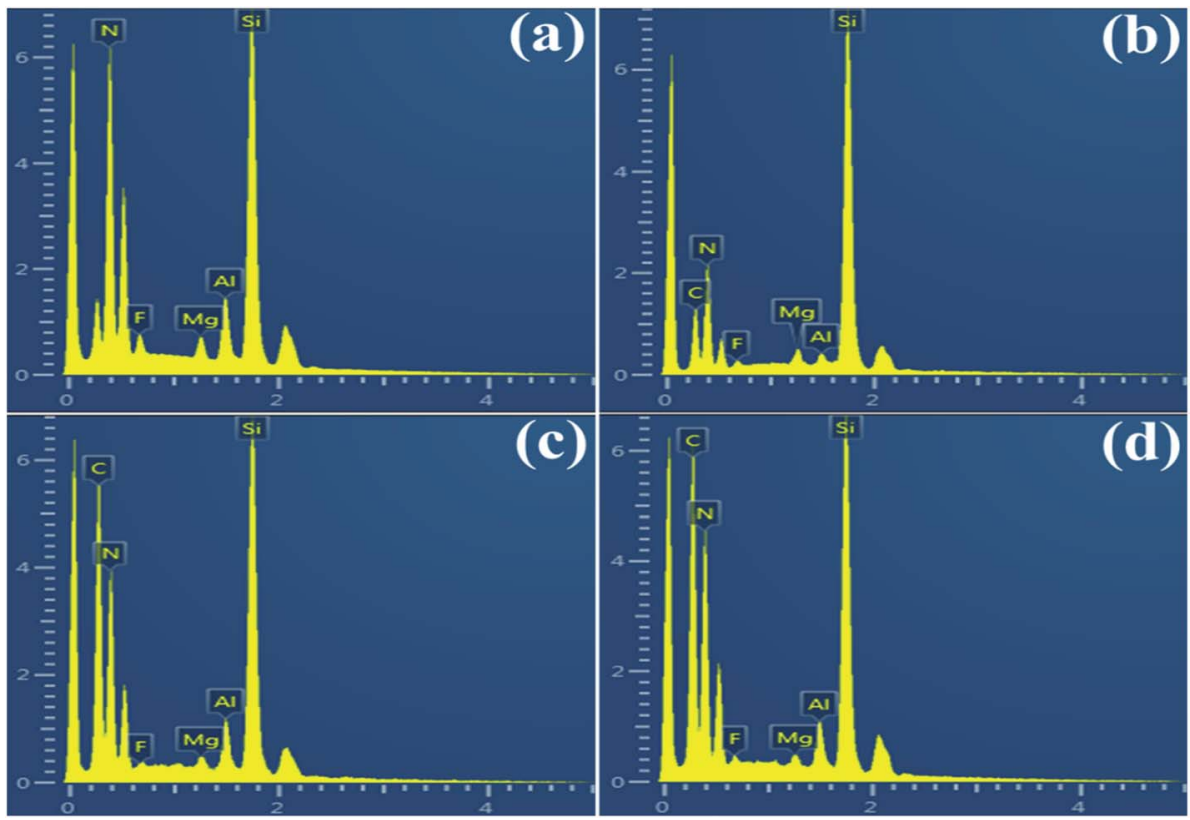

Fig. 3 EDS analysis for GNP/Si ${ }_{3} N_{4}$ composites at 0 wt\% (a), 1 wt\% (b), 2 wt\% (c) and 3 wt\% (d) of GNP.

be observed that the thermal conductivity increased with the increase of GNP content up to $2 \mathrm{wt} \%$ and then slightly decreased at $3 \mathrm{wt} \%$. As shown in Table 1 , the GNP/Si $\mathrm{S}_{3} \mathrm{~N}_{4}$ composites at $2 \mathrm{wt} \%$ of GNP content showed significantly higher thermal conductivity of $137.47 \mathrm{~W} \mathrm{~m}^{-1} \mathrm{~K}^{-1}$, indicating a great increase as compared to $82.42 \mathrm{~W} \mathrm{~m}^{-1} \mathrm{~K}^{-1}$ at $0 \mathrm{wt} \%$ of GNP content. According to Bentsen's report, ${ }^{42}$ the thermal conductivity of a material can decrease with the increase of

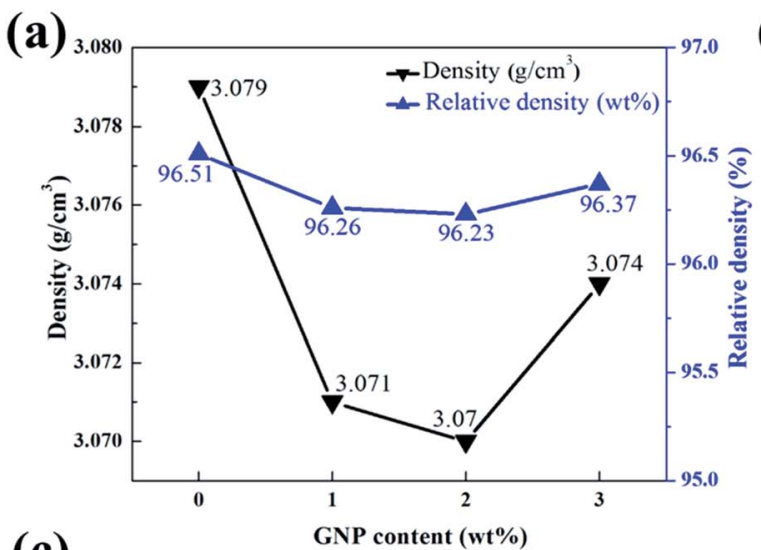

(c)
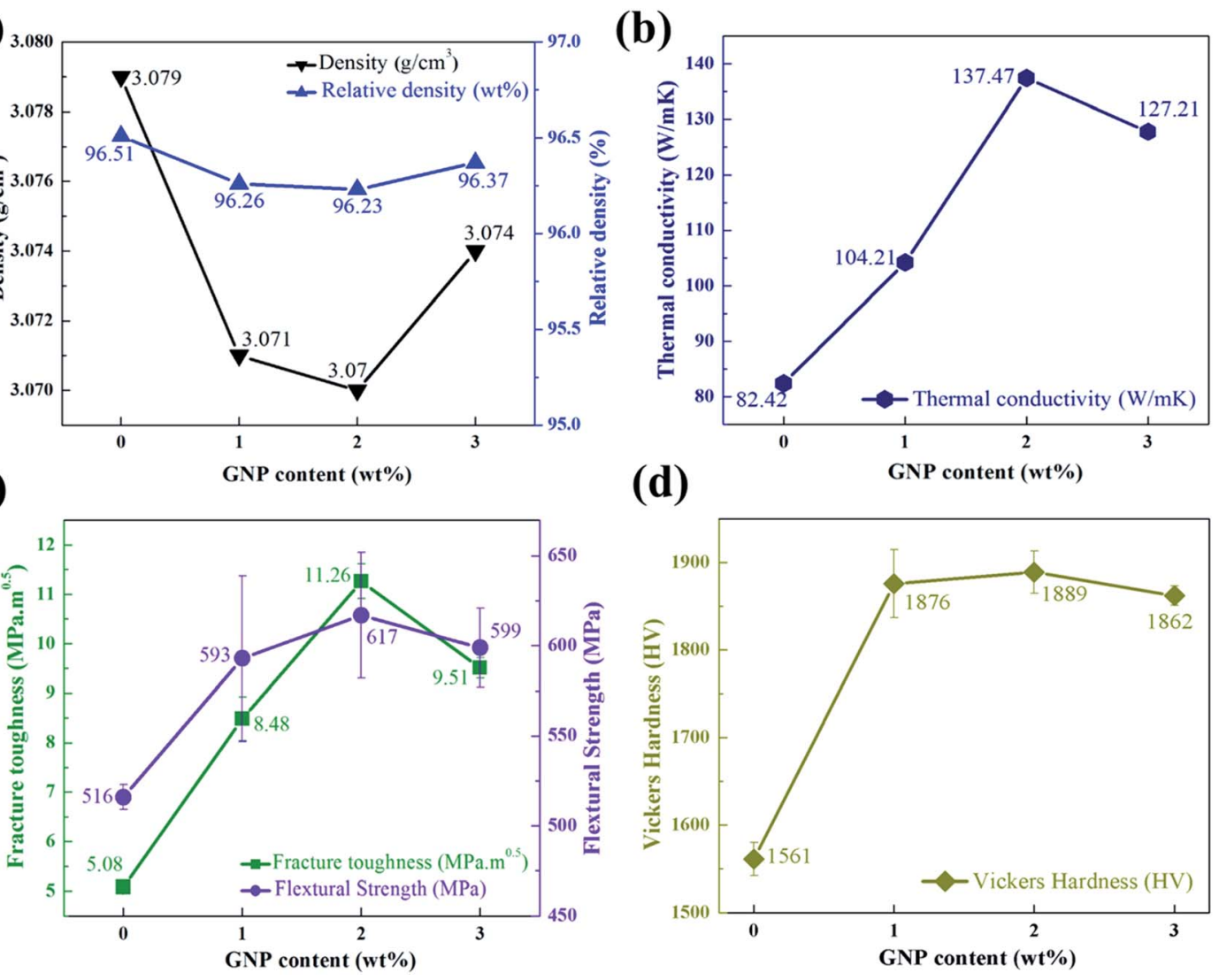

(d)

GNP content (wt\%)

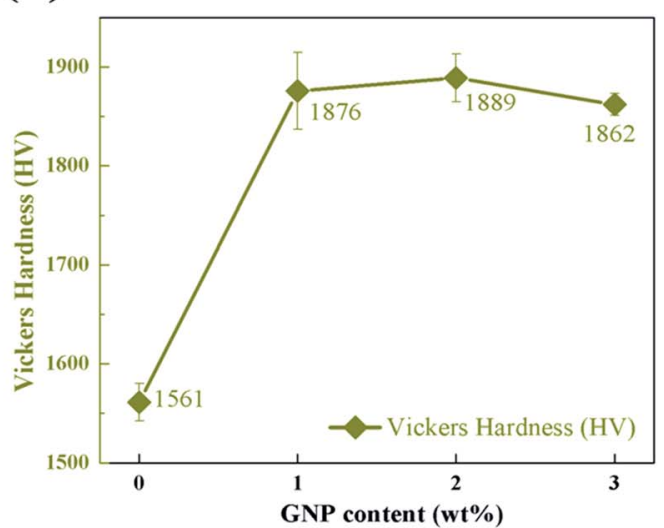

Fig. 4 Density, relative density (a), thermal conductivity (b), fracture toughness and flexural strength (c) and Vickers hardness (d) for GNP/Si $3 \mathrm{~N}_{4}$ composites at different wt\% of GNP. 
phonon scattering produced by solid solution development than that of phonon scattering produced by discrete phases. Thermal conductivities of $\mathrm{GNP} / \mathrm{Si}_{3} \mathrm{~N}_{4}$ composites can also be improved due to the following factors. (1) The lattice oxygen is one of the most unfavorable impurity in thermal conductivity, the reduced lattice oxygen content is critical for increasing density and thermal conductivity. (2) Enhanced grain growth can mitigate the phonon scattering effect caused by grain boundaries, thereby further improving thermal conductivity. (3) The decrease in residual second phase and the increase in continuity of $\mathrm{Si}_{3} \mathrm{~N}_{4} / \mathrm{Si}_{3} \mathrm{~N}_{4}$ also contribute to the improvement of thermal conductivity due to a decrease in the interface thermal resistance. ${ }^{43}$

Over the past two decades, there has been intense research of the reinforcement of monolithic $\mathrm{Si}_{3} \mathrm{~N}_{4}$ ceramics by the microstructural growth. ${ }^{44,45}$ It is essential to highlight that the highest values of fracture toughness in $\mathrm{Si}_{3} \mathrm{~N}_{4}$ ceramics have only been reported for fully transformed $\beta-\mathrm{Si}_{3} \mathrm{~N}_{4}$ materials sintered at high temperature for a long duration in order to avoid phase decomposition and to favor the growth of elongated $\beta-\mathrm{Si}_{3} \mathrm{~N}_{4}$ crystals. As these crystals show an accountable effect on the in situ toughening mechanism, which is owing to the pull out, crack deflection and crack bridging by the grain growth. ${ }^{44}$ The fracture toughness is calculated using eqn (2). ${ }^{46}$

$$
K_{\mathrm{IC}}=\frac{3 P_{\max } L}{2 B W^{3 / 2}} \alpha^{1 / 2} Y
$$

where ' $P$ ' is breaking load, ' $L$ ' is bending span, ' $B$ ' is specimen breadth, ' $W$ ' is specimen height and ' $a$ ' is notch depth, ' $\alpha$ ' is ratio $(a / W)$ and ' $Y$ ' is calibration factor which is calculated by eqn (3). ${ }^{46}$

$$
Y=\frac{1.99-\alpha(1-\alpha)\left(2.15-3.93 \alpha+2.7 \alpha^{2}\right)}{(1+2 \alpha)(1-\alpha)^{3 / 2}}
$$

The flexural strength $\left(\sigma_{\mathrm{f}}\right)$ has been measured by eqn $(4) .{ }^{46}$

$$
\sigma_{\mathrm{f}}=\frac{3 P_{\max } L}{2 B W^{2}}
$$

The values of fracture toughness and flexural strength for $\mathrm{GNP} / \mathrm{Si}_{3} \mathrm{~N}_{4}$ composites can be seen in Fig. $4 \mathrm{c}$. It can be noticed, the fracture toughness and flexural strength improved with the increase of GNP content, whereas decreased with the further increase of GNP contents. In toughness mechanism the crack deflection, crack bridging and pull out of GNP were observed in as-prepared $\mathrm{GNP} / \mathrm{Si}_{3} \mathrm{~N}_{4}$ composites. It is well known that a properly weak grain boundary can be attributed to interfacial de-bonding, which is an important factor to facilitate the crack deflection, crack bridging and pull out of GNP, resulting in high fracture toughness. ${ }^{47}$ Thus, it can be concluded that the grain boundaries were weaker in the initial composites and became strong in the last composite. On the other hand, as the energy of pulling out GNP from the grain boundaries increases, the fracture toughness of the ceramics was subsequently enhanced. However, it has been reported that during HP sintering with an uniaxial pressure, the presence of GNP in the matrix can resist the diffusion and mass transfer of the material through grain boundaries at a high temperature for a long time, resulting in a decrease in strength and the impact of GNP. ${ }^{48} \mathrm{Xia}^{49}$ have fabricated $\mathrm{CNT} / \mathrm{Si}_{3} \mathrm{~N}_{4}$ composites and found that the toughness can be improved by the pullout and crack deflection mechanism. Furthermore, Pasupuleti ${ }^{6}$ have also reported that the fracture toughness of $\mathrm{CNT} / \mathrm{Si}_{3} \mathrm{~N}_{4}$ can be enhanced by the selfreinforcing mechanism. Fig. $4 \mathrm{~d}$ shows the Vickers hardness of $\mathrm{GNP} / \mathrm{Si}_{3} \mathrm{~N}_{4}$ composites with different GNP contents. As illustrated in Table 1, the highest and lowest values of Vickers hardness are 1889 and 1561 (HV), achieved for the composite with $2 \mathrm{wt} \%$ and $0 \mathrm{wt} \%$ of GNP contents, respectively. It is well documented that the $\alpha-\mathrm{Si}_{3} \mathrm{~N}_{4}$ has higher Vickers hardness than that of $\beta-\mathrm{Si}_{3} \mathrm{~N}_{4}$ due to the stacking arrangements of atoms in the crystal lattice. However, the $\beta-\mathrm{Si}_{3} \mathrm{~N}_{4}$ has a higher fracture toughness and flexural strength than $\alpha-\mathrm{Si}_{3} \mathrm{~N}_{4}$, owing to the increase in the ratio of the growth of the rod shaped $\beta$ crystals to the self-toughening of $\mathrm{Si}_{3} \mathrm{~N}_{4} \cdot{ }^{39}$ Henceforth, it can be clearly concluded from this research work that the Vickers hardness of $\mathrm{GNP} / \mathrm{Si}_{3} \mathrm{~N}_{4}$ composites may increases due to the increase of GNP contents. Dusza, ${ }^{18}$ reported an increase in the hardness of multilayer graphene nano-sheets reinforced $\mathrm{Si}_{3} \mathrm{~N}_{4}$ and the decrease in hardness may be due to the residual porosity in material after sintering, similar to that observed in other studies. The higher hardness of GNP/Si $\mathrm{N}_{4}$ composites in this work can also be explained by lower porosity and grain size.

\section{Conclusion}

In this study, $\mathrm{GNP} / \mathrm{Si}_{3} \mathrm{~N}_{4}$ composites containing well distributed GNP with various concentrations were effectively prepared by HP sintering. The XRD results were suggesting the highly crystalline and full phase transformation from $\alpha-$ to $\beta$-Si $\mathrm{N}_{3}$. SEM images showed that the GNP are quite homogeneously distributed in all examined composites, which leads to an increase in the fracture toughness. Moreover, the overall density for all the composites was above $96 \%$, enabled to achieve a substantial improvement in thermal conductivity from 82.42 to $137.47 \mathrm{~W} \mathrm{~m}^{-1} \mathrm{~K}^{-1}$. Also, the flexural strength, fracture toughness, and Vickers hardness of as-prepared composites were increased with the increase of GNP contents and the

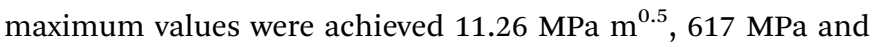
1889 (HV), respectively at $2 \mathrm{wt} \%$ of GNP. The toughness mechanism was alike in all composites in the form of pullout, crack bridging, deflection and branching. The GNP can potentially be used to improve thermal and mechanical performance for a wide range of ceramics to enable their extensive use in highperformance structural applications.

\section{Conflicts of interest}

There are no conflicts to declare.

\section{Acknowledgements}

The authors would like to extend their sincere appreciation to the financial supports from Inorganic Non-metal Institute of 
Shandong University, Shandong Provincial Science and Technology Department Project (No. 31370004011501) and Shandong Province Key Research and Development Program (No. 2016ZDJS05A05) for its funding.

\section{References}

1 K. Jeong, J. Tatami, M. Iijima and T. Takahashi, Ceram. Int., 2016, 42, 11554-11561.

2 O. Borrero-López, A. L. Ortiz, F. Guiberteau and N. P. Padture, J. Eur. Ceram. Soc., 2007, 27, 3351-3357.

3 L. S. Walker, V. R. Marotto, M. A. Rafiee, N. Koratkar and E. L. Corral, ACS Nano, 2011, 5, 3182-3190.

4 M. H. Bocanegra-Bernal and B. Matovic, Mater. Sci. Eng. A, 2010, 527, 1314-1338.

5 L. Xia, T. Zhang, Z. Chai, X. Hu, F. Jin and G. Wen, J. Eur. Ceram. Soc., 2016, 36, 3513-3522.

6 S. Pasupuleti, R. Peddetti, S. Santhanam, K.-P. Jen, Z. N. Wing, M. Hecht and J. P. Halloran, Mater. Sci. Eng. A, 2008, 491, 224-229.

7 K. Hirao, T. Nagaoka, M. E. Brito and S. Kanzaki, J. Am. Ceram. Soc., 1994, 77, 1857-1862.

8 G.-D. Zhan, J. D. Kuntz, J. Wan and A. K. Mukherjee, Nat. Mater., 2002, 2, 38.

9 H. Kim, A. A. Abdala and C. W. Macosko, Macromolecules, 2010, 43, 6515-6530.

10 A. K. Geim and K. S. Novoselov, Nat. Mater., 2007, 6, 183.

11 A. Dato, V. Radmilovic, Z. Lee, J. Phillips and M. Frenklach, Nano Lett., 2008, 8, 2012-2016.

12 G. Wang, J. Yang, J. Park, X. Gou, B. Wang, H. Liu and J. Yao, J. Phys. Chem. C, 2008, 112, 8192-8195.

13 G. Wang, X. Shen, B. Wang, J. Yao and J. Park, Carbon, 2009, 47, 1359-1364.

14 T. Kuilla, S. Bhadra, D. Yao, N. H. Kim, S. Bose and J. H. Lee, Prog. Polym. Sci., 2010, 35, 1350-1375.

15 K. Wang, Y. Wang, Z. Fan, J. Yan and T. Wei, Mater. Res. Bull., 2011, 46, 315-318.

16 P. Kun, O. Tapasztó, F. Wéber and C. Balázsi, Ceram. Int., 2012, 38, 211-216.

17 L. Kvetková, A. Duszová, P. Hvizdoš, J. Dusza, P. Kun and C. Balázsi, Scr. Mater., 2012, 66, 793-796.

18 J. Dusza, J. Morgiel, A. Duszová, L. Kvetková, M. Nosko, P. Kun and C. Balázsi, J. Eur. Ceram. Soc., 2012, 32, 33893397.

19 Y.-J. Park, M.-J. Park, J.-M. Kim, J.-W. Lee, J.-W. Ko and H.-D. Kim, J. Eur. Ceram. Soc., 2014, 34, 1105-1113.

20 Y. Zhou, H. Hyuga, D. Kusano, Y.-i. Yoshizawa, T. Ohji and K. Hirao, J. Asian Ceram. Soc., 2015, 3, 221-229.

21 P. Rutkowski, L. Stobierski and G. Górny, J. Therm. Anal. Calorim., 2014, 116, 321-328.

22 A. A. Balandin, Nat. Mater., 2011, 10, 569.

23 K. M. F. Shahil and A. A. Balandin, Nano Lett., 2012, 12, 861867.

24 F. Kargar, Z. Barani, R. Salgado, B. Debnath, J. S. Lewis, E. Aytan, R. K. Lake and A. A. Balandin, ACS Appl. Mater. Interfaces, 2018, 10, 37555-37565.
25 F. Kargar, Z. Barani, M. Balinskiy, A. S. Magana, J. S. Lewis and A. A. Balandin, Adv. Electron. Mater., 2019, 5, 1800558.

26 J. D. Renteria, D. L. Nika and A. A. Balandin, Appl. Sci., 2014, 4, 525-547.

27 F. Inam, T. Vo and B. R. Bhat, Ceram. Int., 2014, 40, 1622716233.

28 A. Nieto, L. Huang, Y.-H. Han and J. M. Schoenung, Ceram. Int., 2015, 41, 5926-5936.

29 X. Wang, J. Zhao, E. Cui, H. Liu, Y. Dong and Z. Sun, Ceram. Int., 2019, 45, 23384-23392.

30 R. G. Duan, G. Roebben, J. Vleugels and O. Van der Biest, J. Eur. Ceram. Soc., 2002, 22, 1897-1904.

31 A. Saleem, Y. Zhang, H. Gong and M. K. Majeed, Ceram. Int., 2019, 45, 21004-21010.

32 F. Çalışkan, Z. Tatlı, A. Genson and S. Hampshire, J. Eur. Ceram. Soc., 2012, 32, 1337-1342.

33 A. V. Stanishevsky, L. Y. Khriachtchev, R. Lappalainen and M. Räsänen, Diamond Relat. Mater., 1997, 6, 1026-1030.

34 Y. y. Wang, Z. h. Ni, T. Yu, Z. X. Shen, H. m. Wang, Y. h. Wu, W. Chen and A. T. Shen Wee, J. Phys. Chem. C, 2008, 112, 10637-10640.

35 M. S. Dresselhaus, A. Jorio, M. Hofmann, G. Dresselhaus and R. Saito, Nano Lett., 2010, 10, 751-758.

36 H. Porwal, P. Tatarko, S. Grasso, J. Khaliq, I. Dlouhý and M. J. Reece, Carbon, 2013, 64, 359-369.

37 D. L. Zhao, Y. Zhang, H. Gong, L. F. Nie and L. Zhao, Mater. Res. Innov., 2010, 14, 338-341.

38 J. Dusza, G. Blugan, J. Morgiel, J. Kuebler, F. Inam, T. Peijs, M. J. Reece and V. Puchy, J. Eur. Ceram. Soc., 2009, 29, 31773184.

39 Z. Tatlı, F. Çalışkan, J. Butler, C. Crowley and S. Hampshire, Ceram. Int., 2014, 40, 1399-1404.

40 Y. Fan, L. Wang, J. Li, J. Li, S. Sun, F. Chen, L. Chen and W. Jiang, Carbon, 2010, 48, 1743-1749.

41 C. Zhang, X. Yao, Y. Li, H. Liang, J. Chen, J. Zhang, J. Yang, X. Li, T. Qiu, Z. Chen, X. Liu and Z. Huang, Ceram. Int., 2015, 41, 9107-9114.

42 L. D. Bentsen, D. P. H. Haselman and R. Ruh, J. Am. Ceram. Soc., 2006, 66, C-40-C-41.

43 Y. Li, H.-N. Kim, H. Wu, M.-J. Kim, J.-W. Ko, J.-M. Kim, Y.-J. Park, Z. Huang and H.-D. Kim, J. Eur. Ceram. Soc., 2017, 37, 4483-4490.

44 Z. Shen, Z. Zhao, H. Peng and M. Nygren, Nature, 2002, 417, 266.

45 D.-S. Park, B.-D. Hahn, B.-C. Bae and C. Park, J. Am. Ceram. Soc., 2005, 88, 383-389.

46 I. Ahmad, H. Cao, H. Chen, H. Zhao, A. Kennedy and Y. Q. Zhu, J. Eur. Ceram. Soc., 2010, 30, 865-873.

47 Y. Zhou, H. Hyuga, D. Kusano, Y.-i. Yoshizawa and K. Hirao, Adv. Mater., 2011, 23, 4563-4567.

48 Y. Yang, B. Li, C. Zhang, S. Wang, K. Liu and B. Yang, Mater. Sci. Eng. A, 2015, 644, 90-95.

49 Z. Xia, L. Riester, W. A. Curtin, H. Li, B. W. Sheldon, J. Liang, B. Chang and J. M. Xu, Acta Mater., 2004, 52, 931-944. 